\title{
Economic comments on proposal for a novel cancer drug pricing model
}

\author{
Mark J. C. Nuijten and Jan Vis
}

We recently read with interest the article
'Sustainability and affordability of cancer
drugs: a novel pricing model Nat. Rev. Clin. Oncol. 15, 405-406 (2018)'.1. In this article, Uyl-de Groot and Löwenberg describe a model for determining a reasonable price for oncology drugs. This topic is important, as challenging the price of new pharmaceuticals by health authorities has become a new trend owing to the substantial increase of drug prices in the past few years. We would like to comment on several economic assertions made in this paper.

The authors argue that the drug price should be based on the actual costs of research and development (R\&D), other costs, and a fair profit margin. From an economic point of view this is incorrect, as it would mean that a product should always have a price because costs have been incurred in its production. Value is also not similar to prices and costs and, therefore, we also do not favour their use of 'cost plus pricing' for drugs. Moreover, their model does not include the cost of capital and how this is affected by timing differences between investments and receipts. Furthermore, epidemiological variations could lead to each year having a different value in their equation. The model assumes that all eligible patients will use the drug. However, not all eligible patients will be treated and new competitor drugs might later enter the market. Another overestimation is the size of the global market: the population of patients who can realistically expect to receive novel anticancer drugs is far lower, as only economically developed countries currently provide serious markets for pharmaceutical companies.

The application of actual historical costs of R\&D made by Uyl-de Groot and Löwenberg ${ }^{1}$ can also be challenged. In economic valuations the use of historical book-keeping data is not recommended, as such data do not reflect the actual opportunity costs. Another concern is that companies who run their operations efficiently, and thus incur lower costs, will be punished because their lower costs will reduce the drug price determined using the proposed model. The authors justify their exclusion of the R\&D costs of drugs that fail to reach the market because, in the examples of enzalutamide and ruxolitinib, "both drugs were purchased by the vending company" ${ }^{\prime}$. But, in that case, these purchasing prices should be included in the equation, as these might reflect actual R\&D costs and the costs associated with previous risks of treatment failures. Further economic research is required in order to determine the true opportunity costs, which should be applicable when the development, production, and marketing are managed efficiently.

The use of profit in the equation is also a methodological constraint because it is a subjective measure. For example, a company with a limited portfolio of innovative clinical products will not invest in new R\&D programmes, which will lead to lower expenditures and as a consequence higher profit margins. The concept of profit itself is also subject to changes in accounting rules for profit calculation. The authors do not define a 'fair marketing and profit margin', nor do they provide an acceptable threshold: a $30 \%$ margin is used with no explanation of its validity. Another question is 'fair for whom?': the payer, entrepreneur, or investor? Hence, the perspective of the model is not defined, which is essential to informing any model designed to assess drug prices. If the profit margin is correlated with the anticipated level of clinical benefit, a problem could arise if, later, the actual level of benefit deviates materially from the anticipated level of benefit. The authors suggest that the ESMO Magnitude of Clinical Benefit Scale can be used to assess the clinical benefit for oncology drugs, but what measure should be used for non-oncology drugs? If we use other disease-specific scales, are the calculated minimum drug prices comparable? For example, is a minimum price of US\$17,251 for ruxolitinib equivalent to a minimum price of $\$ 17,251$ for an antidepressant? Net present value based on the free cash flows is a more appropriate approach than profit as it takes into account the time value of money. The allocation of fixed costs is also not addressed and might also depend upon the choice of accounting rules.

Methodologically, the proposal's main weakness is that it is inconsistent with economic theory on determining prices.
Microeconomic theory states that investment decisions are 'ex ante' decisions. The economic value of a new product is the net present value of the free cash flows, which are discounted over time by the cost of capital. This cost of capital is not only required by the entrepreneur but also by the investors who donate part of their assets for a short or long time, where the factors of uncertainty and/or risk are important determinants. The cost of capital is a function of the costs of equity and after-tax cost of debt. These rates will reflect the underlying uncertainties and risks facing a company.

The other components consist of a compensation for time and a compensation for changes in purchasing power. The decision to actually commit to a new drug programme is positive if the calculated present value of the net revenue in real terms outweighs the investment required. Only on the basis of this model can decisions be made in an economically responsible manner. The model proposed by the authors is quite distant from that. In a previous paper $^{2}$, we proposed a change in the paradigm in reimbursement decisions on innovative expensive drugs to determine the price of ultra-innovative orphan drugs including the investor's perspective. This paper describes in detail the rationale underlying many of these comments.

We conclude that the implementation of the current model into any legal framework is inappropriate for methodological reasons. This model would require further refinement by all critical stakeholders, including companies and investors.

There is a reply to this correspondence by Uyl de Groot, C. A. \& Löwenberg, B. Nat. Rev. Clin. Oncol. https://doi.org/10.1038/ s41571-018-0084-1 (2018).

$$
\begin{array}{r}
\text { Mark J. C. Nuijten }{ }^{1,2 *} \text { and Jan Vis }{ }^{3,4} \\
{ }^{1} \text { A2M, Amsterdam, Netherlands. } \\
{ }^{2} \text { Istanbul Technical University, Istanbul, Turkey. } \\
{ }^{3} \text { Nyenrode Business University, } \\
\text { Breukelen, Netherlands. } \\
{ }^{4} \text { Talanton, Amsterdam, Netherlands. } \\
{ }^{*} \text { e-mail: mark@a2m.nl } \\
\text { https://doi.org/10.1038/s41571-018-0083-2 }
\end{array}
$$

1. Uyl-de Groot, C. A. \& Löwenberg, B. Sustainability and affordability of cancer drugs: a novel pricing model. Nat. Rev. Clin. Oncol. 15, 405-406 (2018).

2. Nuijten, M. J. C. \& Vis, J. Evaluation and valuation of innovative medicinal products. J. Rare Dis. Res. Treat. 2, 1-11 (2016).

\section{Competing interests}

M.J.C.N. is the founder and owner of A2M, a health economics consultancy firm, and an adjunct professor at Istanbul Technical University (ITU). A2M and ITU had no influence on any aspect of the preparation of this manuscript. J.V. reports that he is an adjunct professor at Nyenrode University and is the owner of Talanton Valuation, a company specializing in business valuations. Talanton had no influence on any aspect of the preparation of this correspondence. This correspondence was written without any direct funding from another party. 